Cite this: J. Mater. Chem. A, 2014, 2 , 215

Received 7th October 2013 Accepted 11th October 2013

DOI: 10.1039/c3ta14021k

www.rsc.org/MaterialsA

\section{Glass-like lattice thermal conductivity and high thermoelectric efficiency in $\mathrm{Yb}_{9} \mathrm{Mn}_{4.2} \mathrm{Sb}_{9} \dagger$}

\author{
Sabah K. Bux, ${ }^{* a}$ Alexandra Zevalkink, ${ }^{\text {b }}$ Oliver Janka, ${ }^{c}$ David Uhl, ${ }^{a}$ Susan Kauzlarich, ${ }^{c}$ \\ Jeffrey G. Snyder ${ }^{b}$ and Jean-Pierre Fleurial ${ }^{a}$
}

Motivated by excellent thermoelectric performance in the well-known Yb-based Zintl compounds $\mathrm{Yb}_{14} \mathrm{MnSb}_{11}$ and $\mathrm{YbZn}_{2-x} \mathrm{Mn}_{x} \mathrm{Sb}_{2}$, this study investigates the thermoelectric properties of $\mathrm{Yb}_{9} \mathrm{Mn}_{4.2} \mathrm{Sb}_{9}$. Unlike most transition metal containing Zintl phases, $\mathrm{Yb}_{9} \mathrm{Mn}_{4.2} \mathrm{Sb}_{9}$ contains a partially occupied $\mathrm{Mn}$ site and thus does not have a valence-precise stoichiometry. Samples were synthesized by direct ball milling of the elements, followed by hot pressing. Consistent with previous reports, X-ray diffraction and wavelength dispersive spectroscopy confirmed a narrow composition range near $\mathrm{Yb}_{9} \mathrm{Mn}_{4.2} \mathrm{Sb}_{9}$. High temperature measurements of the electronic properties of $\mathrm{Yb}_{9} \mathrm{Mn}_{4.2} \mathrm{Sb}_{9}$ indicate that it is a degenerate p-type semiconductor with a band gap sufficiently large for high temperature thermoelectric applications. Hall measurements reveal that $\mathrm{Yb}_{9} \mathrm{Mn}_{4.2} \mathrm{Sb}_{9}$ has a high extrinsic carrier concentration $\left(\sim 10^{20} \mathrm{~h}^{+} \mathrm{cm}^{-3}\right)$, which is due to the deviation from the theoretical "Zintl composition" of $\mathrm{Yb}_{9} \mathrm{Mn}_{4.5} \mathrm{Sb}_{9}$. The measured carrier concentration coincides with the optimum concentration predicted using a single parabolic band model. Measurements of the thermal diffusivity and heat capacity reveal an extremely low, temperature-independent lattice thermal conductivity in this compound $\left(\kappa_{\mathrm{L}}<0.4 \mathrm{~W} \mathrm{mK}^{-1}\right)$, which is due to both the large unit cell size ( 44 atoms per primitive cell) and substantial disorder on the $\mathrm{Mn}$ site. This favorable combination of optimized electronic properties and low lattice thermal conductivity leads to a promising figure of merit at high temperature ( $z T=0.7$ at $950 \mathrm{~K})$.

\section{Introduction}

Solid state thermoelectric energy conversion could be an attractive, environmentally friendly technology for improving the energy efficiency of various terrestrial applications, such as in the waste heat recovery of vehicle exhaust and energy intensive high temperature industrial processes. However, thermoelectric devices are often unsuitable for wide-scale commercial applications due to the low conversion efficiency of thermoelectric materials. The thermoelectric figure of merit $(z T)$ is used to quantify a material's thermal-to-electric energy conversion efficiency:

$$
z T=\frac{\alpha^{2} \sigma T}{\kappa}
$$

${ }^{a}$ Thermal Energy Conversion Technologies Group, Jet Propulsion Laboratory, California Institute of Technology, 4800 Oak Grove Drive, MS 277-207, Pasadena, CA 91109, USA. E-mail: sabah.k.bux@jpl.nasa.gov

${ }^{b}$ Department of Material Science, California Institute of Technology, 1200 E California Blvd, Pasadena, CA 91125, USA

'Department of Chemistry, University of California, Davis, One Shields Ave, Davis, CA 95616, USA

$\dagger$ Electronic supplementary information (ESI) available. See DOI: $10.1039 / \mathrm{c} 3 \operatorname{ta} 14021 \mathrm{k}$ here, $\alpha$ is the Seebeck coefficient, $\sigma$ is the electrical conductivity, and $\kappa$ is the thermal conductivity, which is the sum of the electronic thermal conductivity, $\kappa_{\mathrm{e}}$, and the lattice thermal conductivity, $\kappa_{\mathrm{L}}$. In order for a thermoelectric material to be successful, in addition to a large Seebeck coefficient, it must possess both low, glass-like thermal conductivity and high, metal-like electronic conductivity; two highly conflicting requirements. ${ }^{1}$ Recent efforts to improve the efficiency of thermoelectric materials have relied on several strategies: nanostructuring of traditional heavily-doped semiconductors ${ }^{2}$ to reduce the thermal conductivity, band engineering to enhance the Seebeck coefficient, ${ }^{3}$ and using materials with complex crystal structures that possess intrinsically low lattice thermal conductivities., ${ }^{\mathbf{4 5}}$

The search for new, bulk thermoelectric materials with complex unit cells has led to the discovery of a number of promising new phases such as filled skutterudites ${ }^{6,7}$ and clathrates. ${ }^{8}$ In particular, complex Zintl antimonides have emerged as excellent thermoelectric materials: $:^{\mathbf{9 1 1}}$ the Zintl phase $\mathrm{Yb}_{14} \mathrm{MnSb}_{11}$ currently stands as the most efficient p-type thermoelectric material at high temperatures. ${ }^{12}$ Discovered by Kauzlarich et al. in $1998,{ }^{13} \mathrm{Yb}_{14} \mathrm{MnSb}_{11}$ was shown several years later to be an excellent thermoelectric material with an initial report of $z T=1$ at 1275 K. ${ }^{12}$ Further improvement of synthesis and processing conditions has led to peak $z T$ values as high as 1.4. ${ }^{\mathbf{1 4 , 1 5}}$ 
The high efficiency of $\mathrm{Yb}_{14} \mathrm{MnSb}_{11}$ - a 100\% improvement over state-of-the-art high temperature SiGe alloys ${ }^{16}$ - is primarily due to its extremely low lattice thermal conductivity $\left(\kappa_{\mathrm{L}}\right)$. This stems from its large, complex unit cell, which gives rise to both flattened optical phonon modes and increased Umklapp scattering. ${ }^{5}$ While low $\kappa_{\mathrm{L}}$ is the main motivation for investigating additional Zintl compounds, there are also examples of Zintl antimonides with relatively high electronic mobility; for example, $\mathrm{YbZn}_{2-x} \mathrm{Mn}_{x} \mathrm{Sb}_{2}$ has electronic mobility in excess of $50 \mathrm{~cm}^{2} \mathrm{~V}^{-1} \mathrm{~s}^{-1}$, which leads to $z T$ values above unity. ${ }^{17}$ Inspired by the success of both $\mathrm{Yb}_{14} \mathrm{MnSb}_{11}$ (ref. 12) and $\mathrm{YbZn}_{2-x} \mathrm{Mn}_{x} \mathrm{Sb}_{2}{ }^{18}$ the current study investigates the thermoelectric properties of a relatively new member of the $\mathrm{Yb}$-Mn-Sb Zintl family: $\mathrm{Yb}_{9} \mathrm{Mn}_{4.2} \mathrm{Sb}_{9}$.

$\mathrm{Yb}_{9} \mathrm{Mn}_{4.2} \mathrm{Sb}_{9}$ was first reported by Bobev et al. in 2010. ${ }^{19}$ $\mathrm{Yb}_{9} \mathrm{Mn}_{4.5-x} \mathrm{Sb}_{9}$ forms the same orthorhombic structure type (space group Pbam no. 55) as $\mathrm{A}_{9} \mathrm{Zn}_{4+x} \mathrm{Bi}_{9}$, and $\mathrm{A}_{9} \mathrm{Cd}_{4+x} \mathrm{Bi}_{9}(\mathrm{~A}=$ $\mathrm{Ca}, \mathrm{Sr}, \mathrm{Eu}, \mathrm{Yb})^{20}$ and $\mathrm{A}_{9} \mathrm{Zn}_{4+x} \mathrm{Sb}_{9}(\mathrm{~A}=\mathrm{Yb}, \mathrm{Ca})^{21}$ where $0<x<0.5$. The structure of these compounds, which is related to the $\mathrm{Ca}_{9} \mathrm{Mn}_{4} \mathrm{Bi}_{9}$ structure type, is characterized by infinite $\mathrm{Mn}_{4} \mathrm{Sb}_{9}$ "ribbons" formed from corner sharing $\mathrm{MnSb}_{4}$ tetrahedra. However, as implied by the chemical formulae, the compounds listed above are not perfectly stoichiometric - they contain a partially occupied interstitial transition metal site (white atoms in Fig. 1), which links the neighbouring $\mathrm{Tm}_{4} \mathrm{Sb}_{9}$ ribbons into pseudo two-dimensional layers (Fig. 1b). Each of the above compounds is thought to have a narrow homogeneity range. The initial report on $\mathrm{Yb}_{9} \mathrm{Mn}_{4.5-x} \mathrm{Sb}_{9}$ by Bobev et al. suggests that there is a narrow stable composition range near $\mathrm{Yb}_{9} \mathrm{Mn}_{4.2} \mathrm{Sb}_{9}-$ corresponding to $\sim 10 \%$ occupancy of the Mn interstitial site.

To date, investigations of $\mathrm{Yb}_{9} \mathrm{Mn}_{4.5-x} \mathrm{Sb}_{9}$ and related compounds have been confined primarily to crystallographic studies. Several studies of the transport properties have been reported, but a thorough investigation of the thermoelectric properties of these intriguing materials has not yet been made. The unique structural complexity caused by the Mn defect structure in $\mathrm{Yb}_{9} \mathrm{Mn}_{4.5-x} \mathrm{Sb}_{9}$ is expected to lead to exceptionally low lattice thermal conductivity, and thus provides additional motivation for this study. Here we describe a novel means of synthesizing $\mathrm{Yb}_{9} \mathrm{Mn}_{4.5-x} \mathrm{Sb}_{9}$ and we report for the first time on its high temperature thermoelectric properties and figure of merit.

\section{Experimental}

$\mathrm{Yb}_{9} \mathrm{Mn}_{4.2} \mathrm{Sb}_{9}$ was synthesized via direct ball milling and sintering of elemental precursors. A stoichiometric amount of the constituent elements were loaded into a $65 \mathrm{ml}$ steel ball mill vial (Spex industries) with 3-12.7 $\mathrm{mm}$ steel ball bearings under an argon atmosphere and then milled for 1 hour using a Spex industries mixer-mill to a homogenous powder. The resulting powder was compacted with hot uniaxial compaction using graphite dies (POCO HPD-1) under a pressure of $160 \mathrm{MPa}$ and a temperature of $1100 \mathrm{~K}$. The geometric densities of the pressed cylindrical pellets were $\sim 99 \%$ of the theoretical density. For thermoelectric transport characterization, the pellets were sliced using a low speed diamond blade saw into $1 \times 12.7 \mathrm{~mm}$ discs.

The thermoelectric properties were measured on both custom and commercial apparatuses. The Seebeck coefficient was measured using the light-pipe method with tungsten-niobium thermocouples under high vacuum in a custom set up. ${ }^{28}$ Temperature dependent Hall coefficient and resistivity (Van der Pauw 4-point probe) were measured using a $0.8 \mathrm{~T}$ magnet with tungsten pressure contact probes. ${ }^{29}$ Thermal diffusivity was measured using a Netzsch LFA 404 system. The temperature was limited to $1000 \mathrm{~K}$ to prevent sublimation of the samples during measurements. All transport measurements were taken during both heating and cooling (heating rate of $180 \mathrm{~K} \mathrm{~h}^{-1}$ ), and showed

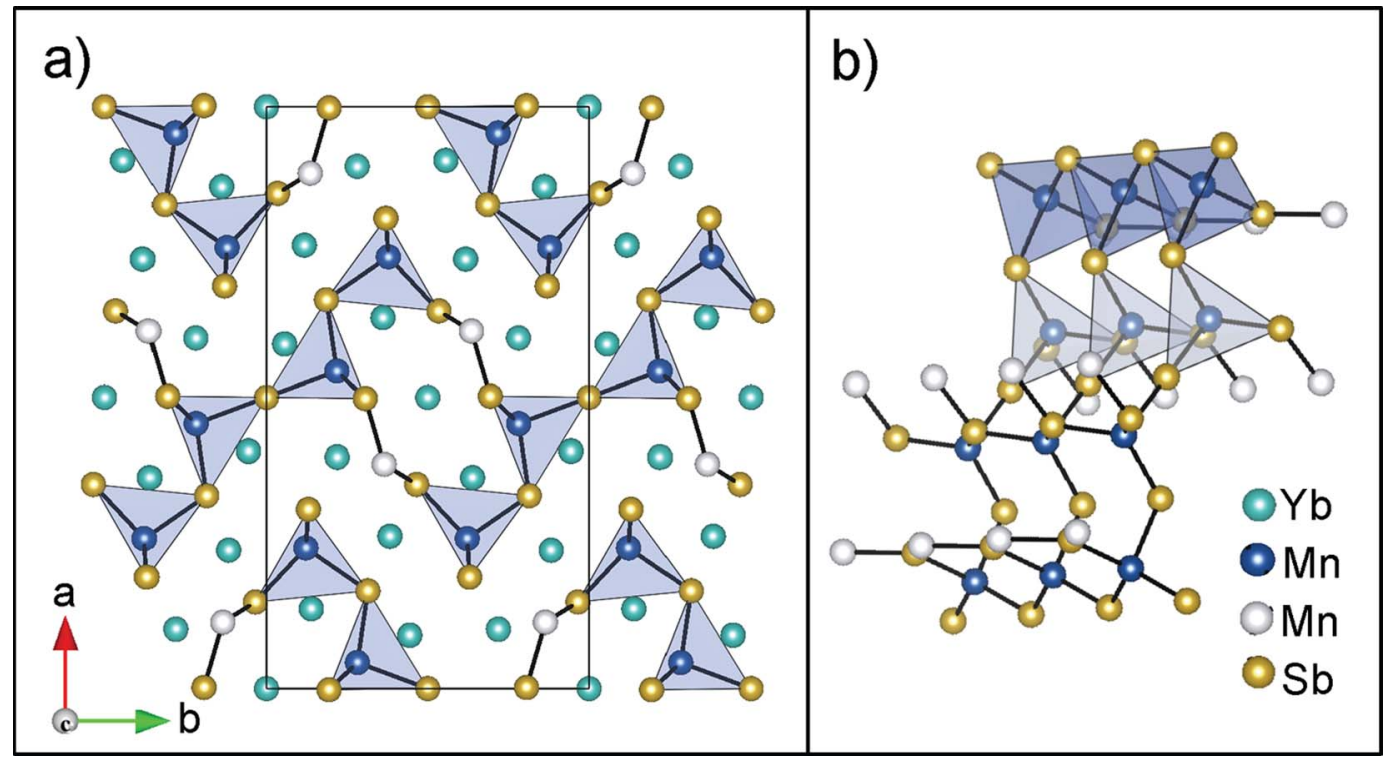

Fig. 1 (a) The structure of $\mathrm{Yb}_{9} \mathrm{Mn}_{4+x} \mathrm{Sb}_{9}$ consists of "ribbons" of corner sharing $\mathrm{MnSb}_{4}$ tetrahedra. Neighboring ribbons are covalently linked by $\mathrm{Mn}$ interstitial sites, which are $10 \%$ occupied. (b) Each individual ribbon is infinitely long in the $c$-direction and four tetrahedra wide. Yb atoms are shown in light blue, Mn atoms in dark blue (100\% occupation) or white (10\% occupation), and Sb atoms are yellow. 
no hysteresis. The combined measurement uncertainty in the thermoelectric figure of merit is generally assumed to be $\sim 20 \%$.

\section{Results and discussion}

\subsection{Synthesis and characterization}

The $\mathrm{Yb}_{9} \mathrm{Mn}_{4.2} \mathrm{Sb}_{9}$ phase was successfully synthesized using ball milling and sintering processes similar to that described in ref. 14. Ball milling was used to homogenize the elements and reduce the diffusion path length, but did not result in the formation of the desired ternary phase. Instead, the final phase was formed and sintered during the hot pressing step. The resulting samples were fully dense (geometric, 99\% theoretical), capable of holding a mirror finish, and stable in air. Powder X-ray diffraction using $\mathrm{Cu} \mathrm{K}$ alpha radiation was used to characterize a representative sample. The simulated pattern Rietveld refinement (ESI Table $1 \dagger$ ) and diffracted pattern are in excellent agreement, suggesting that the sample is $\sim 99 \%$ $\mathrm{Yb}_{9} \mathrm{Mn}_{4.2} \mathrm{Sb}_{9}$ phase (Fig. 2a). Electron microprobe analysis (EPMA) of the samples confirmed the formation of the $\mathrm{Yb}_{9} \mathrm{Mn}_{4.2} \mathrm{Sb}_{9}$ phase with less than 1 volume\% impurities of $\mathrm{Yb}_{14} \mathrm{MnSb}_{11}$ and $\mathrm{YbMn}_{2} \mathrm{Sb}_{2}$ (Fig. 2b) (ESI Table $2 \dagger$ ).

Efforts were also made to synthesize samples with compositions close to $\mathrm{Yb}_{9} \mathrm{Mn}_{4.5} \mathrm{Sb}_{9}$ (the valence-precise "Zintl composition"), but the resulting samples contained a large fraction of impurity phases. This suggests to us that this phase has a narrow composition range near $\mathrm{Yb}_{9} \mathrm{Mn}_{4.2} \mathrm{Sb}_{9}$, consistent with the initial report by Bobev et al. ${ }^{19}$ For high temperature transport measurements, two separately prepared samples (referred to as sample A and B) with compositions of approximately $\mathrm{Yb}_{9} \mathrm{Mn}_{4.2} \mathrm{Sb}_{9}$ were used, both of which had similar, low concentrations of impurity phases $(\sim 1 \%)$ as verified by EPMA.

\subsection{Electronic properties}

The composition of the samples in this study $\left(\mathrm{Yb}_{9} \mathrm{Mn}_{4.2} \mathrm{Sb}_{9}\right)$ is Mn-deficient relative to the valence-precise "Zintl composition" of $\mathrm{Yb}_{9} \mathrm{Mn}_{4.5} \mathrm{Sb}_{9}$. Each "missing" $\mathrm{Mn}$ corresponds to two "missing" electrons - leading to a Fermi level well below the valence band maximum. Consistent with this understanding, the observed electronic properties of the samples in this study (described below in detail) are indicative of a heavily doped, degenerate p-type semiconductor. Hall measurements reveal a large p-type carrier concentration of $n_{\mathrm{H}} \sim 2 \times 10^{20} \mathrm{~h}+\mathrm{cm}^{-3}$ (shown in Fig. 3a for samples A and B). The carrier concentration, $n$, is independent of temperature, indicative of extrinsic conduction. The resistivity, $\rho$, increases with temperature like a metal due to the decreasing Hall mobility (Fig. 3b). Above $600 \mathrm{~K}$, the Hall mobility $(\mu=\rho /$ $\left.n_{\mathrm{H}} \mathrm{e}\right)$ decreases approximately with a T-1 dependence (red curve in Fig. 3c) as expected when acoustic phonon scattering is the dominant scattering mechanism. Below $600 \mathrm{~K}$, additional scattering mechanisms may be responsible for the decrease of $\mu$ from the T- 1 dependence. ${ }^{22}$

As shown in Fig. 3d, the Seebeck coefficient $(\alpha)$ of $\mathrm{Yb}_{9} \mathrm{Mn}_{4.2} \mathrm{Sb}_{9}$ increases with increasing temperature up to $T=$ $1000 \mathrm{~K}$, indicative of a heavily doped semiconductor with no noticeable mixed conduction effects. This also confirms that $\mathrm{Yb}_{9} \mathrm{Mn}_{4.2} \mathrm{Sb}_{9}$ has a band gap sufficiently large for high temperature thermoelectric applications. To obtain a lower limit for the band gap, we employ $E_{\mathrm{g}}=2 \alpha_{\max } T_{\max }$, which yields $E_{\mathrm{g}} \sim 0.4 \mathrm{eV}$. These results are consistent with the initial study of $\mathrm{Yb}_{9} \mathrm{Mn}_{4.2} \mathrm{Sb}_{9}$ by Bobev et al., which suggested that the material was either heavily doped or metallic, and predicted a pseudogap at the Fermi level. However, the current study is the first to show high thermopower in this material, confirming both the presence of a band gap and the material's suitability as a thermoelectric material.

When compared with the well known Zintl phase $\mathrm{Yb}_{14} \mathrm{MnSb}_{11}$, the electronic behavior of $\mathrm{Yb}_{9} \mathrm{Mn}_{4.2} \mathrm{Sb}_{9}$ is quite similar; both have large carrier concentrations and behave as heavily doped semiconductors. While the higher carrier concentration in $\mathrm{Yb}_{14} \mathrm{MnSb}_{11}$ leads to lower resistivity $(\sim 2 \mathrm{~m} \Omega$ $\mathrm{cm}$ at $300 \mathrm{~K}$ ) than found in $\mathrm{Yb}_{9} \mathrm{Mn}_{4.2} \mathrm{Sb}_{9}$, the Seebeck coefficients of the two compounds are nearly identical. This suggests
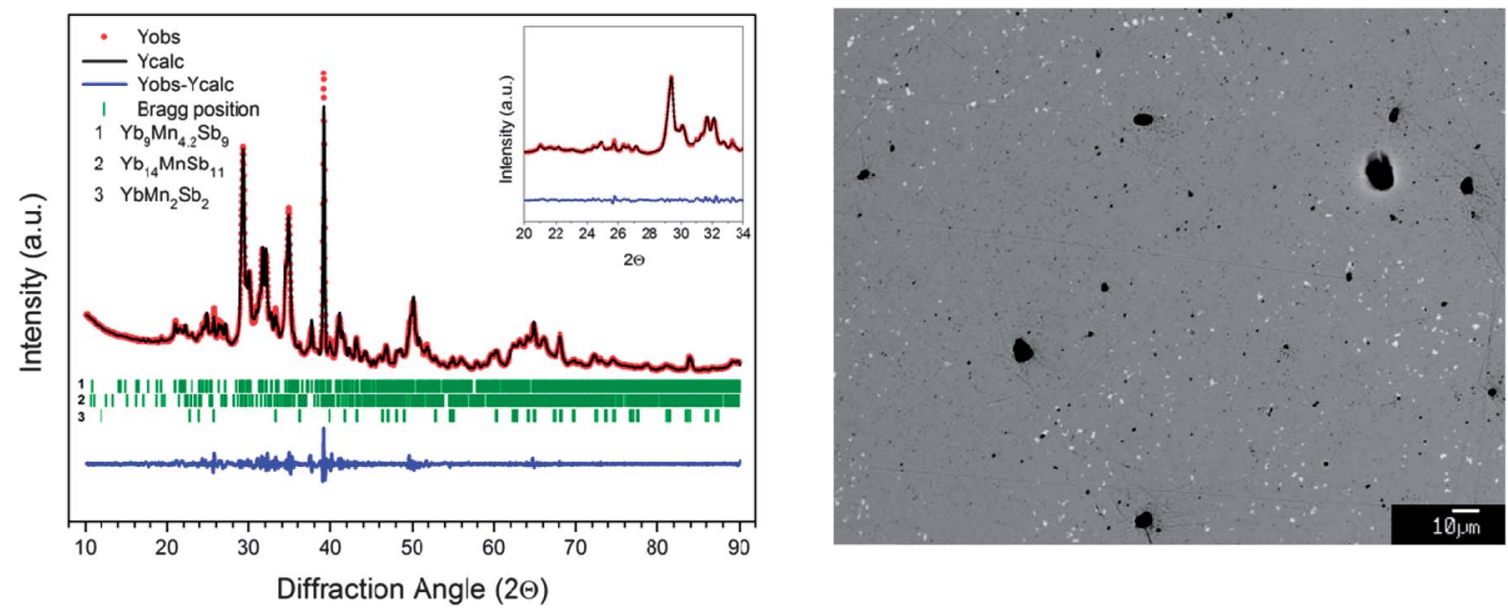

Fig. 2 (a) XRD pattern of $\mathrm{Yb}_{9} \mathrm{Mn}_{4.2} \mathrm{Sb}_{9}$ confirms the high phase purity of the material, with only 1 percent of the $\mathrm{Yb}_{14} \mathrm{MnSb}_{11}$ and $\mathrm{YbMn}_{2} \mathrm{Sb}_{2}$ present as a secondary phase. (b) A representative $\mathrm{SEM}$ image shows the secondary phases as small white $\left(\mathrm{Yb}_{14} \mathrm{MnSb}_{11}\right)$ and dark grey $\left(\mathrm{YbMn}_{2} \mathrm{Sb}_{2}\right)$ precipitates. 

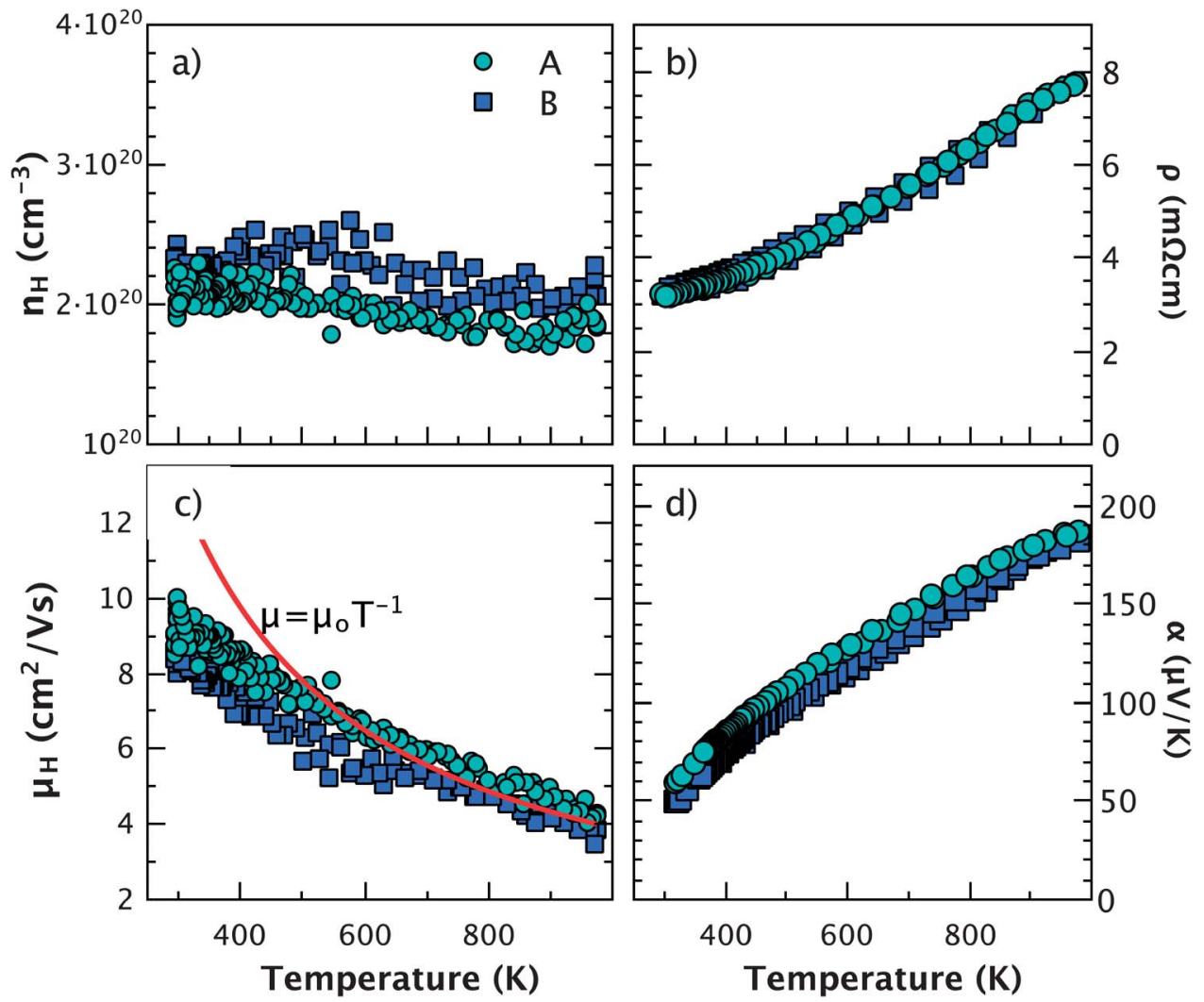

Fig. 3 (a) The Hall carrier concentration, (b) resistivity, (c) Hall mobility, and (d) Seebeck coefficient of $\mathrm{Yb}_{9} \mathrm{Mn}_{4.2} \mathrm{Sb}_{9}$ are all indicative of a degenerate $\mathrm{p}$-type semiconductor. The maximum value of the Seebeck coefficient suggests that the band gap is $0.4 \mathrm{eV}$ or greater.

that the density of states effective mass of $\mathrm{Yb}_{14} \mathrm{MnSb}_{11}$ is significantly larger than that of $\mathrm{Yb}_{9} \mathrm{Mn}_{4.2} \mathrm{Sb}_{9}$.

\subsection{Thermal transport properties}

The thermal conductivity, $\kappa_{\text {total }}$, was calculated from the measured thermal diffusivity, $D$, using $\kappa_{\text {total }}=D d \mathrm{C}_{\mathrm{p}}$, where $d$ is the geometric density, and $\mathrm{C}_{\mathrm{p}}$ is simply the Dulong-Petit heat capacity $\left(\mathrm{C}_{\mathrm{p}}=\right.$ $0.192 \mathrm{~J} \mathrm{~g}^{-1} \mathrm{~K}^{-1}$ ). The thermal conductivity of $\mathrm{Yb}_{9} \mathrm{Mn}_{4.2} \mathrm{Sb}_{9}$, shown in Fig. 4a for samples A and B, is remarkably low, ranging from 0.7 $\mathrm{W} \mathrm{mK}{ }^{-1}$ at room temperature to $0.6 \mathrm{~W} \mathrm{mK}^{-1}$ at $1000 \mathrm{~K}$.

To estimate the electronic thermal conductivity $\left(\kappa_{\mathrm{e}}=L T / \rho\right)$, the Lorentz number $(L)$ was calculated assuming a single parabolic band structure. The experimental Seebeck coefficients were used to calculate the chemical potential, which, in turn, determined the Lorentz number values, shown in the inset of Fig. 4b. Subtracting $\kappa_{\mathrm{e}}$ from $\kappa_{\text {total }}$ yields the lattice thermal conductivity, $\kappa_{\mathrm{L}}$. In both samples, the lattice thermal conductivity decreases from 0.45 at $300 \mathrm{~K}$ to less than $0.4 \mathrm{~W} \mathrm{mK}^{-1}$ at high temperature. This extremely low, largely temperature independent, lattice thermal conductivity is comparable to that of a glass.

An estimate of the lower bound for the lattice thermal conductivity was made using eqn (2), where $V$ is the average atomic volume and $\nu_{\mathrm{T}}$ and $\nu_{\mathrm{L}}$ are the transverse and longitudinal speeds of sound, respectively. This model assumes a minimum scattering length as a function of phonon frequency, and is often described as the glassy limit of the lattice thermal conductivity. ${ }^{23}$

$$
\kappa_{\min }=\frac{1}{2}\left(\frac{\pi}{6}\right)^{\frac{1}{3}} k_{\mathrm{B}} V^{-\frac{2}{3}}\left(2 \nu_{\mathrm{T}}+\nu_{\mathrm{L}}\right)
$$

Room temperature ultrasonic measurements of $\mathrm{Yb}_{9} \mathrm{Mn}_{4.2} \mathrm{Sb}_{9}$ yielded $\nu_{\mathrm{L}}=3070 \mathrm{~m} \mathrm{~s}^{-1}$ and $\nu_{\mathrm{T}}=1730 \mathrm{~m} \mathrm{~s}^{-1}$ respectively. From these, an effective Debye temperature of $189 \mathrm{~K}$ was calculated.

In many complex Zintl compounds the lattice thermal conductivity decreases with the $\mathrm{T}^{-1}$ dependence expected for Umklapp scattering, approaching $\kappa_{\min }$ only at high temperatures. ${ }^{24-26}$ In $\mathrm{Yb}_{9} \mathrm{Mn}_{4.2} \mathrm{Sb}_{9}$ however, the lattice thermal conductivity reaches $\kappa_{\min }$ near room temperature, and remains essentially flat up to $1000 \mathrm{~K}$, at which point a slight increase occurs due to the onset of bipolar conduction. To emphasize the exceptionally low $\kappa_{\mathrm{L}}$ of $\mathrm{Yb}_{9} \mathrm{Mn}_{4.2} \mathrm{Sb}_{9}$, Fig. 5 compares $\mathrm{Yb}_{9} \mathrm{Mn}_{4.2} \mathrm{Sb}_{9}$ with state-of-the-art thermoelectric materials $\left(\mathrm{PbTe}^{27} \mathrm{Si}_{0.8} \mathrm{Ge}_{0.2}{ }^{22}\right.$ ) and complex Zintl phases $\left(\mathrm{Yb}_{14} \mathrm{MnSb}_{11}{ }^{15} \mathrm{Sr}_{3} \mathrm{GaSb}_{3}{ }^{24}\right)$. Note that for the latter three compounds $\kappa_{\mathrm{L}}$ was calculated using the Dulong-Petit heat capacity and Lorenz numbers calculated using an SPB model, allowing for an objective comparison.

The low, flat $\kappa_{\mathrm{L}}$ in $\mathrm{Yb}_{9} \mathrm{Mn}_{4.2} \mathrm{Sb}_{9}$ likely arises from two main mechanisms; a large unit cell, and a high degree of disorder on the interstitial $\mathrm{Mn}$ site. With approximately 44 atoms per unit cell, the phonon dispersion of $\mathrm{Yb}_{9} \mathrm{Mn}_{4.2} \mathrm{Sb}_{9}$ has a large number of low velocity optical modes. These optical modes contribute minimally to the lattice thermal conductivity due to their low group velocity, 

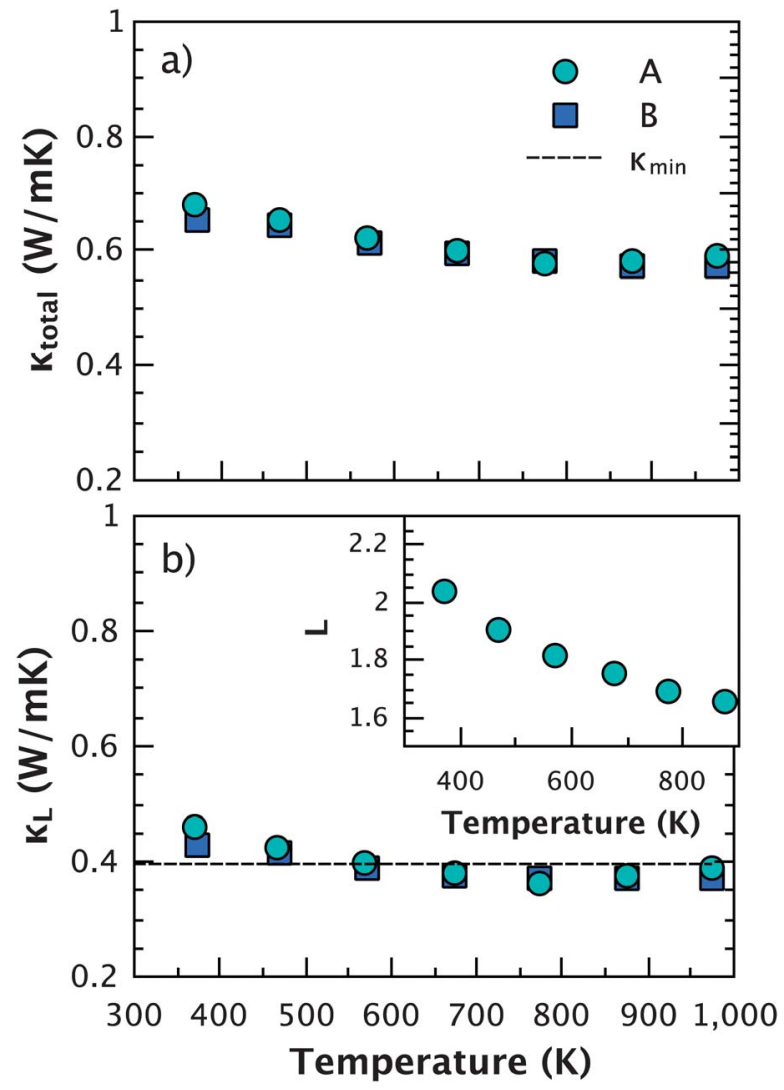

Fig. 4 (a) The thermal conductivity of $\mathrm{Yb}_{9} \mathrm{Mn}_{4.2} \mathrm{Sb}_{9}$ is nearly temperature independent. (b) Subtracting the electronic contribution $\left(\kappa_{\mathrm{e}}=\right.$ $L T / \rho$ ) yields the lattice thermal conductivity, which is at or below $\kappa_{\min }$ across the entire temperature range.

and also lead to additional Umklapp scattering. In $\mathrm{Yb}_{9} \mathrm{Mn}_{4.2} \mathrm{Sb}_{9}$, $\kappa_{\mathrm{L}}$ is also reduced by point defect scattering by the $\sim 10 \%$ occupied Mn interstitial site. This temperature-independent effect likely

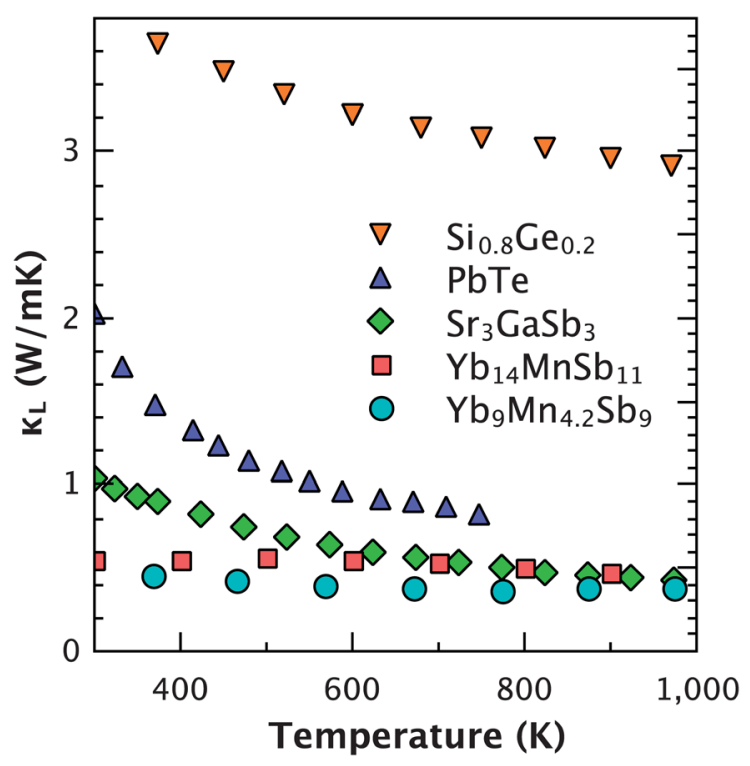

Fig. 5 A comparison of the lattice thermal conductivity of state of the art materials $\left(\mathrm{PbTe}^{27} \mathrm{Si}_{0.8} \mathrm{Ge}_{0.2}{ }^{22}\right)$ and complex Zintl compounds $\left(\mathrm{Sr}_{3} \mathrm{GaSb}_{3}{ }^{24}\right.$ $\left.\mathrm{Yb}_{14} \mathrm{MnSb}_{11}{ }^{15}\right)$ highlights the exceptionally low $\kappa_{\mathrm{L}}$ in $\mathrm{Yb}_{9} \mathrm{Mn}_{4.2} \mathrm{Sb}_{9}$. plays a significant role in reducing $\kappa_{\mathrm{L}}$ even at low temperatures. While the small concentration of $\mathrm{YbMn}_{2} \mathrm{Sb}_{2}$ and $\mathrm{Yb}_{14} \mathrm{MnSb}_{11}$ impurities may also play a role in reducing the lattice thermal conductivity in $\mathrm{Yb}_{9} \mathrm{Mn}_{4.2} \mathrm{Sb}_{9}$ samples, this is likely a minor effect. In addition, most reported Zintl phase thermoelectric materials contain similar concentrations of impurities without exhibiting flat $\kappa_{\mathrm{L}}$.

\subsection{Figure of merit}

The figure of merit $(z T)$ of $\mathrm{Yb}_{9} \mathrm{Mn}_{4.2} \mathrm{Sb}_{9}$, shown in Fig. 6, was calculated using polynomial fits to the measured $\rho, \alpha$, and $\kappa$. The $z T$ of both samples reaches 0.7 at $950 \mathrm{~K}$, making this a promising high temperature p-type material. In contrast to most recent reports of high $z T$ values in Zintl compounds, $\mathrm{Yb}_{9} \mathrm{Mn}_{4.2} \mathrm{Sb}_{9}$ exhibits nearly optimal electronic properties without the need for chemical doping. A single band model, described in ref. 26 , was used to predict an optimized $z T$ at a carrier concentration of $n=1 \times 10^{20} \mathrm{~h}+\mathrm{cm}^{-3}$, which is slightly lower than the naturally occurring hole concentration of $n_{\mathrm{H}}=2$ $\times 10^{20} \mathrm{~h}+\mathrm{cm}^{-3}$. The model assumes $T=970 \mathrm{~K}$, an effective mass of $m^{*}=1.2 m_{\mathrm{e}}$, intrinsic mobility of $\mu_{\mathrm{o}}=5 \mathrm{~cm}^{2} \mathrm{~V}^{-1} \mathrm{~s}^{-1}$,

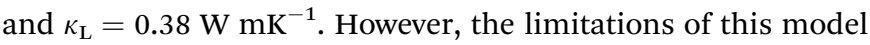
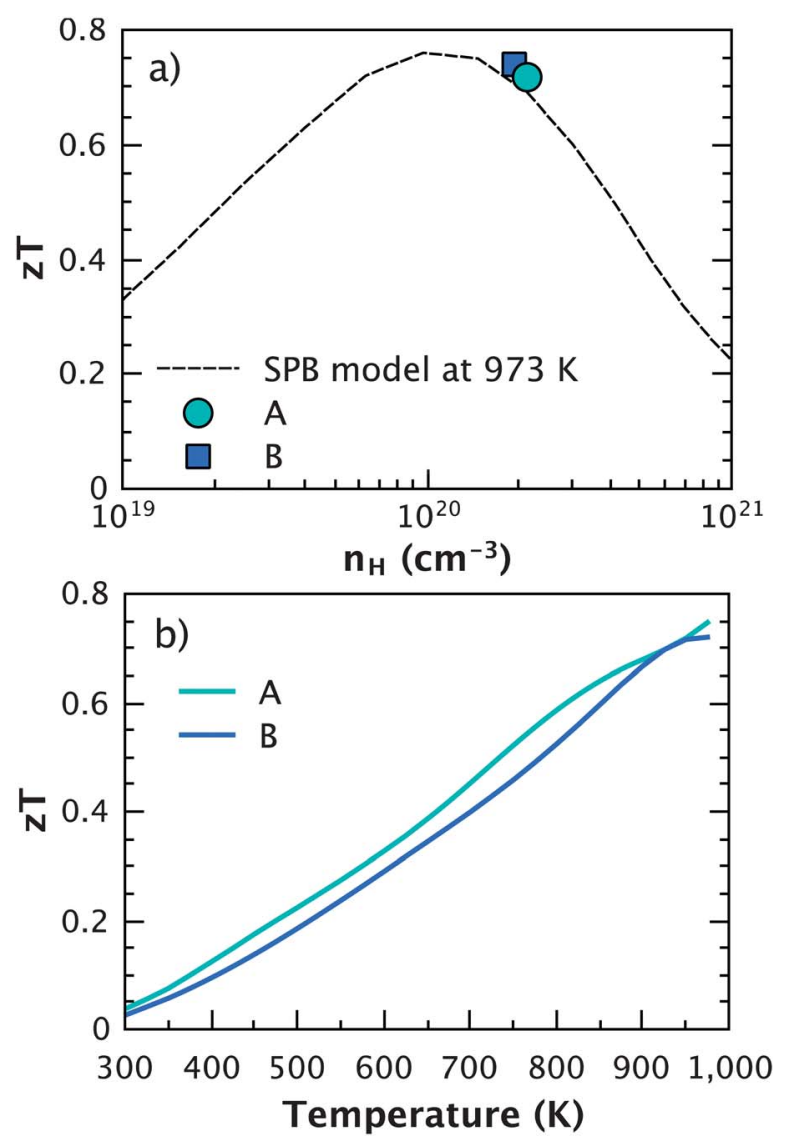

Fig. 6 (a) The optimal carrier concentration predicted using an SPB model $\left(T=973 \mathrm{~K}, m^{*}=1.2 m_{\mathrm{e}}, \mu_{\circ}=5 \mathrm{~cm}^{2} \mathrm{~V}^{-1} \mathrm{~s}^{-1}\right)$ is slightly less than that of $\mathrm{Yb}_{9} \mathrm{Mn}_{4.2} \mathrm{Sb}_{9}$ samples. (b) The figure of merit of $\mathrm{Yb}_{9} \mathrm{Mn}_{4.2} \mathrm{Sb}_{9}$ samples increase linearly with temperature to up to a maximum of 0.7 at $900 \mathrm{~K}$. 
leave some uncertainty in the optimal value of $n$, and the ability to control or reduce $n$ may lead to further optimization of $z T$. Since the interstitial Mn content in $\mathrm{Yb}_{9} \mathrm{Mn}_{4.2} \mathrm{Sb}_{9}$ appears to have a very narrow range, varying the $\mathrm{Mn}$ content is not a likely route to controlling $n$. In contrast, in the isostructural $\mathrm{Zn}$-analogue $\left(\mathrm{Yb}_{9} \mathrm{Zn}_{4+x} \mathrm{Sb}_{9}\right)$, a wider composition range may be possible, ${ }^{\mathbf{1 9 , 2 1}}$ suggesting that a solid solution between these may be a potential route to controlling $n$ and increasing the performance of this system.

\section{Conclusions}

Bulk $\mathrm{Yb}_{9} \mathrm{Mn}_{4.2} \mathrm{Sb}_{9}$ samples were successfully synthesized by ball milling followed by hot pressing. Attempts to synthesize samples with varying Mn content were unsuccessful, suggesting that this phase has a narrow composition range near $\mathrm{Yb}_{9} \mathrm{Mn}_{4.2} \mathrm{Sb}_{9}$. Though not intentionally doped, the $\mathrm{Yb}_{9} \mathrm{Mn}_{4.2} \mathrm{Sb}_{9}$ samples were found to behave as heavily doped semiconductors with high p-type carrier concentration and metallic resistivity, due to the samples' Mn-deficiency relative to the valence-precise Zintl composition $\left(\mathrm{Yb}_{9} \mathrm{Mn}_{4.5} \mathrm{Sb}_{9}\right)$. The measured Seebeck coefficient was found to be large, positive, and increasingly linearly with temperature, indicating a suitably large band gap $(>0.4 \mathrm{eV})$ for high temperature thermoelectric applications. Additionally, the lattice thermal conductivity in $\mathrm{Yb}_{9} \mathrm{Mn}_{4.2} \mathrm{Sb}_{9}$ is extremely low, due to both its large unit cell (44 atoms) and the large degree of disorder on the interstitial $\mathrm{Mn}$ site. The observed carrier concentration in $\mathrm{Yb}_{9} \mathrm{Mn}_{4.2} \mathrm{Sb}_{9}$ coincides closely with the optimal concentration predicted using a single parabolic band model, leading to a peak $z T$ of 0.7 at $950 \mathrm{~K}$, without the need for additional doping.

\section{Acknowledgements}

The authors would like to thank Dr Thierry Caillat for his helpful discussions. They would also like to thank Leslie D. Zoltan, George Nakatsukasa and Dr Pawan Gogna for their assistance in sample characterization and measurement. This work was performed at the Jet Propulsion Laboratory, California Institute of Technology under contract with the National Aeronautics and Space Administration. This work was supported by the NASA Science Missions Directorate's Radioisotope Power Systems Technology Advancement Program.

\section{References}

1 G. J. Snyder and E. S. Toberer, Nat. Mater., 2008, 7, 105.

2 S. K. Bux, J.-P. Fleurial and R. B. Kaner, Chem. Commun., 2010, 46, 8311-8324.

3 Y. Pei, A. D. LaLonde, H. Wang and G. J. Snyder, Energy Environ. Sci., 2012, 5, 7963-7969.

4 G. A. Slack, Solid State Physics, Academic Press, New York, 1979.
5 E. S. Toberer, A. Zevalkink and G. J. Snyder, J. Mater. Chem., 2011, 21, 15843.

6 G. Nolas, J. Cohn and G. A. Slack, Phys. Rev. B: Condens. Matter Mater. Phys., 1998, 58, 164-170.

7 T. Calliat, A. Borshchevsky and J. P. Fleurial, J. Appl. Phys., 1996, 80, 4442-4449.

8 J. Cohn, G. Nolas, V. Fessatidis, T. H. Metcalf and G. A. Slack, Phys. Rev. Lett., 1999, 82, 779-782.

9 E. S. Toberer, A. F. May, B. C. Melot, E. Flage-Larsen and G. J. Snyder, Dalton Trans., 2010, 39, 1046-1054.

10 S. M. Kauzlarich, S. R. Brown and G. J. Snyder, Dalton Trans., 2007, 2099-2107.

11 E. S. Toberer, A. F. May and G. J. Snyder, Chem. Mater., 2010, 22, 624-634.

12 S. R. Brown, S. M. Kauzlarich, F. Gascoin and G. J. Snyder, Chem. Mater., 2006, 18, 1873-1877.

13 J. Y. Chan, M. M. Olmstead, S. Kauzlarich and D. J. Webb, Chem. Mater., 1998, 10, 3583-3588.

14 K. Star, A. Zevalkink, C.-K. Huang, B. Dunn and J. P. Fleurial, Mater. Res. Soc. Symp. Proc., 2010, 1267.

15 J.-A. Paik, E. Brandon, T. Calliat, R. Ewell and J. P. Fleurial, Proceedings of Nuclear and Emerging Technologies for Space, 2011.

16 B. Abeles, D. S. Beers, G. D. Cody and J. P. Dismukes, Phys. Rev., 1962, 125, 44-46.

17 K. Guo, Q.-G. Cao, X.-J. Feng, M.-B. Tang, H.-H. Chen, X. Guo, L. Chen, Y. Grin and J.-T. Zhao, Eur. J. Inorg. Chem., 2011, 2011, 4043-4048.

18 C. Yu, T. J. Zhu, S. N. Zhang, X. B. Zhao, J. He, Z. Su and T. M. Tritt, J. Appl. Phys, 2008, 104, 013705.

19 S.-Q. Xia and S. Bobev, Chem. Mater., 2009, 22, 840-850.

20 S.-Q. Xia and S. Bobev, J. Am. Chem. Soc., 2007, 129, 1001110018.

21 S. Bobev, J. D. Thompson, J. L. Sarrao, M. M. Olmstead, H. k. Hope and S. M. Kauzlarich, Inorg. Chem., 2004, 43, 5044-5052.

22 C. B. Vining, J. Appl. Phys, 1991, 69, 4333-4340.

23 D. Cahill, S. Watson and R. Pohl, Phys. Rev. B: Condens. Matter Mater. Phys., 1992, 46, 6131-6140.

24 A. Zevalkink, W. G. Zeier, G. Pomrehn, E. Schechtel, W. Tremel and G. J. Snyder, Energy Environ. Sci., 2012, 5, 9121.

25 E. S. Toberer, A. Zevalkink, N. Crisosto and G. J. Snyder, Adv. Funct. Mater., 2010, 20, 4375-4380.

26 A. May, E. Toberer, A. Saramat and G. Snyder, Phys. Rev. B: Condens. Matter Mater. Phys., 2009, 80, 12.

27 A. D. LaLonde, Y. Pei and G. J. Snyder, Energy Environ. Sci., 2011, 4, 2090.

28 C. Wood, D. Zoltan and G. Stapfer, Rev. Sci. Instrum., 1985, 56, 719.

29 K. A. Borup, E. S. Toberer, L. D. Zoltan, G. Nakatsukasa, M. Errico, J. P. Fleurial, B. B. Iverson and G. J. Snyder, Rev. Sci. Instrum., 2012, 83, 123902. 